\title{
Medium Sized Stocky Titanosaur from South Asia
}

\author{
Muhammad Sadiq Malkani \\ Geological Survey of Pakistan, Muzaffarabad, Azad Kashmir, Pakistan \\ Email: malkanims@yahoo.com
}

How to cite this paper: Malkani, M.S. (2019) Medium Sized Stocky Titanosaur from South Asia. Open Journal of Geology, 9, 631-634.

https://doi.org/10.4236/ojg.2019.910060

Received: August 16, 2019

Accepted: September 21, 2019

Published: September 24, 2019

Copyright (c) 2019 by author(s) and Scientific Research Publishing Inc. This work is licensed under the Creative Commons Attribution International License (CC BY 4.0).

http://creativecommons.org/licenses/by/4.0/ (c) (i) Open Access

\begin{abstract}
Recently, four coexisted titanosaurs from latest Maastrichtian Vitakri Lameta Formation of Indo-Pakistan are recognized as Isisaurus and Pakisaurus of large-sized slender pakisaurids, Saraikimasoom and Gspsaurus of the smallest and medium sized transversely stocky gspsaurids. Gspsaurus pakistani based on associated skull (with conical teeth tapering gradually from base to tip), vertebral and appendicular elements found from Alam 19 locality of Vitakri area, Barkhan district, Balochistan, Pakistan, South Asia. Gspsaurus bears sufficient skeletal elements and can be used for evolutionary studies.
\end{abstract}

\section{Keywords}

Medium Sized Stocky Titanosaur, Associated Skeleton, Latest Maastrichtian, South Asia

\section{Introduction}

Gspsaurus pakistani medium sized stocky titanosaur as a new genus and new species was reported by [1] and formally published by [2]. For phylogeny, this is being described here.

\section{Gspsaurus pakistani Medium Sized Titanosaur of Indo-Pakistan}

Systematic paleontology of Gspsaurus pakistani is as follows. Dinosauria, Saurischia, Sauropoda, Titanosauria, Gspsauridae [2], Gspsaurinae [2], Gspsaurus [1] [2], Gspsaurus pakistani [1] [2] (Figure 1). Gspsaurus pakistani as a new genus and new species was first described by [1] and later on formally published by [2]. Gspsaurus pakistani holotypic skull and lectotypic braincase, vertebrae and 

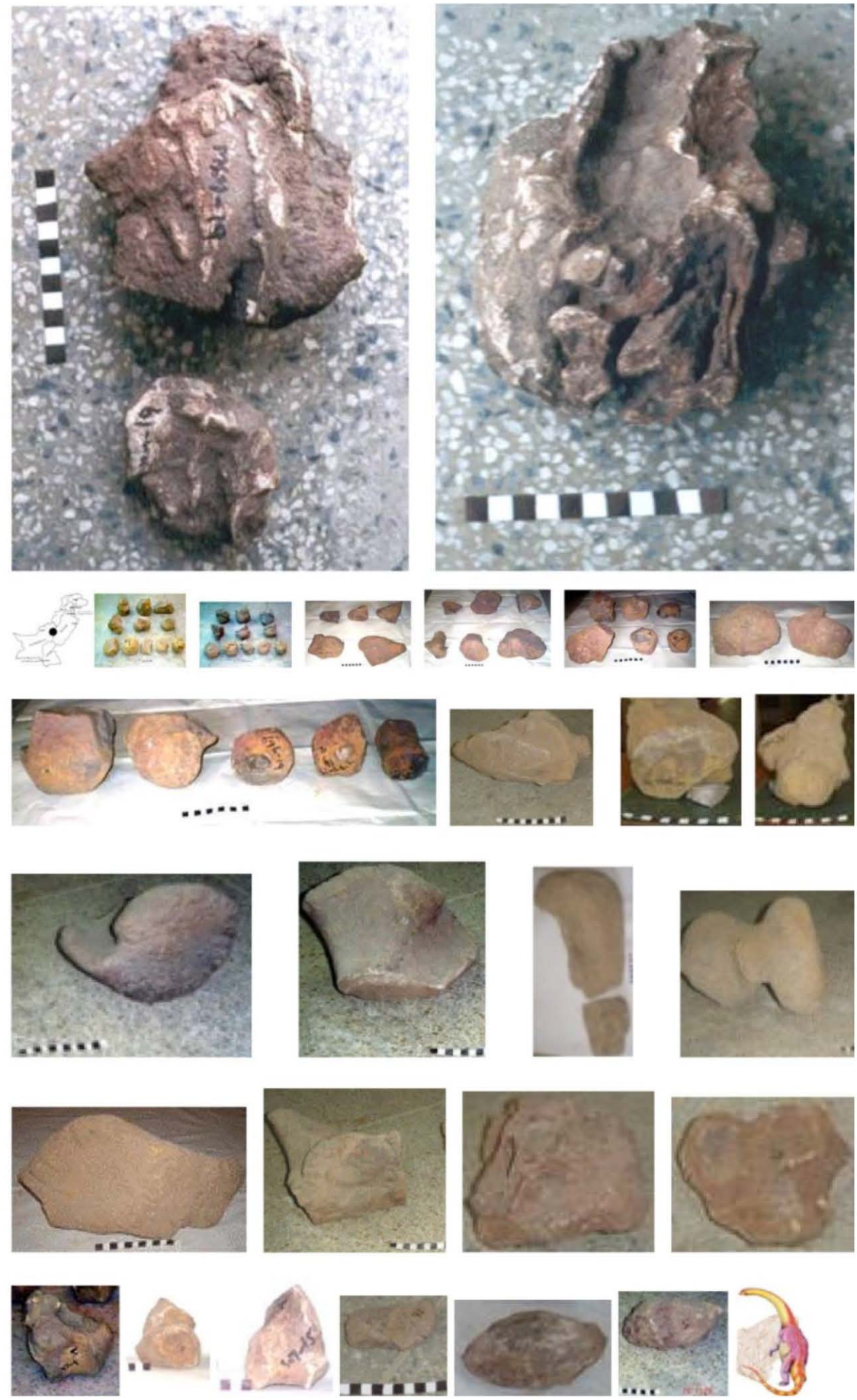

Figure 1. Gspsaurus pakistani fossils. Row 1, holotypic skull MSM-79-19 and MSM-80-19 from Alam locality in ventral and posterior views. Row 2, photo 1, Map of Pakistan (black circle represent Alam type locality); photo 2-7, lectotypic fossils from Alam. Row 3, lectotypic fossils from Alam locality. Row 4, referred fossils, proximal tibia in 2 views, proximal and distal femur. Row 5, distal expanded scapula, pubis, and atlas-axis in 2 views. Row 6, mid caudal, trispinous distal caudal in 2 views, armour mosaic plate, large oval two plates (armour or ungual). Scale each black digit is $1 \mathrm{~cm}$. Last photo represents model of Gspsaurus vitakri (fossil based) or Pashtosaurus zhobi (track based model managed by Mr. Nicholas Allen British Journalist and prepared by Dr. Dmitry Bogdanov). 
appendicular elements (Figure 1) from Alam 19 type locality, and referred postcranial fossils from Top Kinwa 16, South Kinwa 4, Mari Bohri 15, Rahi Wali 10 and Darwaza 8 localities found in latest Maastrichtian Vitakri Lameta Formation of Fort Munro Group, Barkhan District, Balochistan, Pakistan. Some fossils from Vitakri Lameta Formation of India are also referred. These fossils are housed in the museum of Geological Survey of Pakistan, Quetta. Genus Gspsaurus honors the Geological Survey of Pakistan, and saurus means lizard. The species name $G$. pakistani honors the country of origin Pakistan. The pronunciation of Gspsaurus is G. S. P. saurus.

\subsection{Diagnosis of Gspsaurus pakistani Medium Sized Stocky Titanosaur}

Gspsaurus pakistani medium sized sauropod shares with the Titanosauria as vertebrae lacking hyposphene-hypantrum articulations; procoelous caudals (except the first caudal); forward insertion of neural arches on caudals; and prominent olecranon process. Gspsaurus pakistani autapomorphies are as small sized spongy skull; teeth circular to subcircular, slender, slightly recurved and conical. The thickness of diameter decreases gradually from base to tip; palatal shelf between the ventral palatal process and dorsal palatal process forms left and right maxillary canals; dorsal palatal shelf just below the left and right premaxillae and between the dorsal palatal processes forms reverse triangular premaxillary canal; some teeth cone blunted showing wear facet, broad $U$ shaped upper teeth row and $\mathrm{V}$ shaped lower teeth row. Reversed V-shaped ventral palatal processes with oval shaped rod contacted week with maxilla; V-shaped small dorsal palatal processes attached on the contact of maxilla and premaxilla. Dentary ramus anterior depth is slightly less than mid length, dentary with long anteroposterior symphyses, angled $15^{\circ}$ or more anteriorly to axis of jaw ramus, transversely thick and anteroposteriorly lense shaped proximal tibia and transversely oval shaped distal tibia.

\subsection{Description of Gspsaurus pakistani Medium Sized Stocky Titanosaur}

Skull is small sized and spongy. Teeth are circular to subcircular, slender, slightly recurved and conical-taper gradually from base to tip. Premaxilla is without anterior step. Ventral palatal shelf forms left and right maxillary canals. Dorsal palatal shelf forms one premaxillary canal. Premaxillary canal is enclosed dorsally by both fellow of premaxillae, ventrally and laterally by dorsal palatal processes. Premaxillary canal is high angled $V$ shaped. Upper teeth row as broad $U$ shaped and lower teeth row as V-shaped. Dentary ramus is thick, tall and pneumatic. Dentary ramus anterior depth is slightly less than dentary at mid length. Dentary has long anteroposteriorly symphyses. Dentary symphysis, angled $15^{\circ}$ or more anteriorly to jaw axis. Reversed V-shaped palatal with long limb, and V-shaped dorsal palatal hook with short limbs attached on the contact of maxilla and pre- 
maxilla. Braincase is large size with quadrangle shaped basioccipital condyles with median cut on dorsal and ventral views. Basioccipital condyle is constricted dorsoventrally in the middle; Lateral side of basioccipital condyle is generally straight (unlike Indian braincases). Basal tubera have high angle unlike Indian titanosaur braincases (similar to Rapetosaurus braincase from Madagascar). Atlas-axis is very broad, pneumatic and have many pleurocoels on lateral and posterior views. Axis centrum is about twice broad than height. Axis parapophysis is rectangular located posteriorly on ventral aspect of centrum. Axis diapophysis is thick and located posteriorly on the lateral sides of centrum just posterior of the pleurocoel. Axis pleurocoel has inclined thin bony septa in mid. Anterior cervical is small and broad, and mid cervical is very broad and large. Parapophysis is changed from rectangular (in anterior cervical) to oval (in middle and posterior cervicals. Neural spine is not bifid. Cervical and dorsal centra are opisthocoelous. First caudal centrum is ball like and has anterior and posterior articular balls (biconvex). Full middle caudal series is heavy and slightly tall and at the end squarish with ventral view slightly compressed than dorsal view of centrum. Distal caudal is cylindrical with restricted ball. Distalmost caudal centrum forming caudal cap have anterior well developed concavity while posterior ball is trispinous, two spines directing downward and one spine directing upward or vice versa. Chevron is simple. Chevron arch and chevron spine anteroposteriorly compressed. Distal scapula is expanded well. Medial extrusion of proximal humerus prominent. Medially non-deflected proximal femur is like Saraikimasoom (and unlike Pakisaurus and Isisaurus). Distal femur has maximum expansion. Femur distal condyles have rugosities on ventral surfaces which extended on laterally and medially. Transversely thick and anteroposteriorly lense shaped proximal tibia. Proximal condyle of stocky tibia has broad groove or depression on dorsal view. Lateral fibular condyle of proximal tibia is symmetric (while tilted in Pakisaurus). Distal tibia transversely oval shaped. Tibia and fibula closely articulated. Dorsoventrally compressed large oval plate may be osteoderms (or ungual which provide the best support for stocky body (and also fit by footprints of basal and most advanced titanosaurs from Pakistan.

\section{Conflicts of Interest}

The author declares no conflicts of interest regarding the publication of this paper.

\section{References}

[1] Malkani, M.S. (2014) Titanosaurian Sauropod Dinosaurs from Latest Cretaceous of Pakistan. $2^{\text {nd }}$ Symposium of IGCP 608 "Cretaceous of Asia", Tokyo, Japan, 4-6 September 2014, 108-111.

[2] Malkani, M.S. (2015) Dinosaurs, Mesoeucrocodiles, Pterosaurs, New Fauna and Flora from Pakistan. Geological Survey of Pakistan, Information Release No. 823, $1-32$. 